\title{
Theoretical Investigations of Ti-Based Binary Shape Memory Alloys
}

\author{
Rita John', Hannah Ruben ${ }^{2,3}$ \\ ${ }^{1}$ Department of Theoretical Physics, University of Madras, Chennai, India; ${ }^{2}$ Post Graduate Department of Physics, Women's Chris- \\ tian College, Chennai, India; ${ }^{3}$ Mother Teresa Women's University, Kodaikanal, India. \\ Email: rita_john@sify.com, hancath2007@yahoo.co.in
}

Received June $15^{\text {th }}, 2011$; revised July $8^{\text {th }}, 2011$; accepted August $17^{\text {th }}, 2011$.

\begin{abstract}
The electronic structure and ground state properties of TiX $(X=F e, N i, P d, P t$ and $\mathrm{Cu})$ type Shape Memory alloys have been calculated using the self consistent Tight-Binding Linear Muffin Tin Orbital (TB-LMTO) method. The systematic total energy studies made on TiX alloys in both B2 and (B19/B19') structures successfully explain the structural stability of these compounds. The equilibrium lattice parameters, bulk moduli $\left(B_{o}\right)$, cohesive energy $\left(E_{c o h}\right)$ and heat of formation $(\Delta H)$ are calculated for these systems and compared with the available experimental and other theoretical results. The bonding nature of these TiX alloys is analyzed via the density of states (DOS) histogram.
\end{abstract}

Keywords: Shape Memory Alloys, TB-LMTO, B2-B19 Phases, Structural Parameters

\section{Introduction}

Martensitic alloys have been a hot topic for several decades due to shape memory effect and many other peculiar properties present during their martensitic phase transformation [1,2]. A lot of experimental and theoretical works have been devoted to study this phenomenon yet many aspects of the transformation are still elusive. It has stimulated many investigations in exploring the difference in electronic structure of different structural phases involved in the transformation from martensite phase (B19/B19') to austenite phase (B2).

To investigate Martensitic phase transformation from the electronic point of view, Ye et al. [3] have used first principles total energy calculations to show some interesting correlations between the relative stability of B2 and (B19/B19') phases with the electronic structure for TiNi, TiPd and TiPt alloys.

The main objective of the paper is to study the electronic and structural properties of $\mathrm{TiX}(\mathrm{X}=\mathrm{Fe}, \mathrm{Ni}, \mathrm{Pd}, \mathrm{Pt}$ and $\mathrm{Cu}$ ) alloys in both (B2) and (B19/B19') phases calculated using the self consistent Tight-Binding Linear Muffin Tin Orbital (TB-LMTO) method. The paper is divided into six sections. Section 2 gives a brief outline of the computational details of the Tight-Binding Linear Muffin Tin Orbital scheme. The results of the total energy calculations obtained for cubic (B2) and orthorhombic/monoclinic (B19/B19') phases of TiX alloys are presented in Section 3. The band structure and density of states (DOS) for TiX (X = Fe, Ni, Pd, Pt and $\mathrm{Cu}$ ) alloys in both phases are reported in Section 4. Section 5 deals with the theoretically calculated cohesive energy, heat of formation which are compared with the experimentally reported available values. The bulk modulus values obtained for the alloys using the universal equation of state (UEOS) analysis are reported in Section 6. The important conclusions arrived from the above studies are given in the last Section.

\section{Method of Calculation}

The band structure and total energy studies are made within the atomic-sphere approximation by means of Tight Binding-Linear Muffin Tin Orbital method (TBLMTO) [4], which is the exact transformation of Andersen's linear muffin-tin orbitals [5] to localize shortranged or tight-binding orbitals. The potential is calculated within the density-functional prescription under local-density approximation (LDA) using the parameterization scheme of von Barth and Hedin [6]. The TB (screened) representation of the LMTO method makes the computation fast for the following reasons: 1) the MTO's are linear in energy and hence, unlike the augmented plane-wave or Korringa-Kohn-Rostoker methods we can get the eigen values within single diagonalization; 2) a solution to an eigen value equation of size only $9 \times 9$ 
(for $\mathrm{s}, \mathrm{p}, \mathrm{d}$ electron elements) per atom at each point in reciprocal space is required; 3) The screened structure constant for each atom needs only up to second-nearestneighbor atoms. In the band structure calculations, the valence electronic configurations for TiFe, TiNi, TiPd, TiPt and TiCu are as Ti: $3 \mathrm{~d}^{2} 4 \mathrm{~s}^{2}, \mathrm{Ni}: 3 \mathrm{~d}^{8}, 4 \mathrm{~s}^{2}, \mathrm{Pd}: 4 \mathrm{~d}^{10}, \mathrm{Pt}$ : $5 \mathrm{~d}^{9} 6 \mathrm{~s}^{1}$ and $\mathrm{Cu}: 3 \mathrm{~d}^{10}, 4 \mathrm{~s}^{1}$ respectively. They are chosen to represent the basis set for our calculations. The $d$ electrons are treated as valence electrons unlike earlier pseudopotential based calculations. In our calculations, the s, $\mathrm{p}, \mathrm{d}$ partial waves have been used (i.e., maximum angular momentum $1_{\max }=2$ ). Apart from this, the combined correction terms are also included, which account for the non-spherical shape of the atomic cells and the truncation of higher partial waves $(1>2)$ inside the sphere so as to minimize the errors in the LMTO method. To exclude additional freedom in the choice of computational parameters the same Weigner-Seitz (WS) radius is chosen for all atoms and the calculated overlaps between the various atomic spheres in this WS radius are within the allowed range of the atomic-sphere approximation. The atomic position coordinates used for $\mathrm{B} 2$ and $\mathrm{B} 19$ structures are $(0,0,0),(0.5,0.5,0.5)$ and $(0,0,0)$ and $(0.5$, $0.0,0.5)$ all alloys respectively.

The tetrahedron method for the Brillouin zone (i.e., $k$ space) integration has been used with its latest version, which avoids misweighing and corrects error due to the linear approximation of the bands inside each tetrahedron [7].

\section{Total Energy Calculations}

In order to determine the phase stability of both $\mathrm{B} 2$ and
(B19/B19') crystal structures in Figure 1, we have calculated the total energy for each alloy with different lattice constants in the reduced and extended experimental volumes for all the compounds. The self consistent iterations were carried out with an accuracy of $10^{-4}$ Ryd for eigen values, using $96 k$ points in the irreducible wedge of the first Brillouin zone (IBZ) of orthorhombic/monoclinic structures and $72 k$ points in the IBZ of cubic structures.

The total energy curves for TiX ( $\mathrm{X}=\mathrm{Fe}, \mathrm{Ni}, \mathrm{Pd}$, Pt and $\mathrm{Cu})$ alloys in B2 and (B19/B19') structures for different reduced and extended volumes are shown in Figure 2. The equilibrium lattice constants of the above mentioned systems in both phases are calculated. From Table 1, the theoretically obtained equilibrium lattice constants are underestimated compared to the experimental values [8],

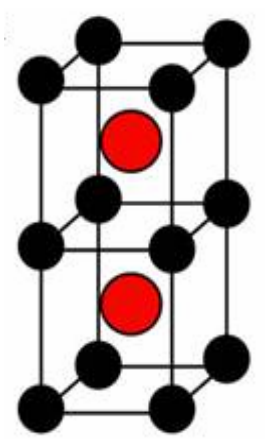

(a)

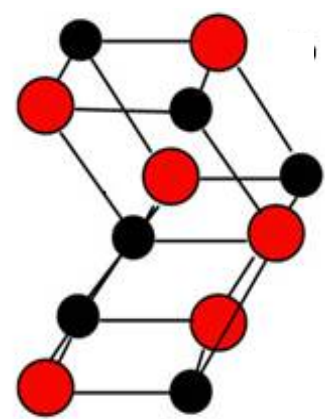

(b)
Figure 1. (a) Austenite (B2) lattice structure and (b) martensite (B19/B19') lattice structure.

Table 1. Experimental and Theoretical lattice constants $(a, b, c)$ in $\AA$ of $\mathrm{Ti} X(\mathrm{X}=\mathrm{Fe}, \mathrm{Ni}, \mathrm{Pd}, \mathrm{Pt}, \mathrm{Cu})$ alloys.

\begin{tabular}{|c|c|c|c|c|c|c|c|c|c|c|}
\hline \multirow{2}{*}{ Alloy } & \multirow{2}{*}{ Type } & $\mathrm{a}$ & \multirow{2}{*}{$\frac{\mathrm{b}}{\text { Present work }}$} & \multirow[t]{2}{*}{$\mathrm{c}$} & \multicolumn{3}{|c|}{ Theoretical } & \multicolumn{3}{|c|}{ Experimental } \\
\hline & & & & & $\mathrm{a}$ & $\mathrm{b}$ & $\mathrm{c}$ & $\mathrm{a}$ & $\mathrm{b}$ & $\mathrm{c}$ \\
\hline \multirow{2}{*}{$\mathrm{TiFe}$} & B2 & 2.9156 & & & $2.987^{[\mathrm{a}]}$ & & & $2.976^{[\mathrm{a}]}$ & & \\
\hline & B19 & 2.7581 & 4.4204 & 3.934 & & & & & & \\
\hline \multirow[t]{3}{*}{ TiNi } & B2 & 2.9714 & & & $3.023^{[\mathrm{a}]}$ & & & $3.015^{[\mathrm{a}]}$ & & \\
\hline & B19 & 2.512 & 4.028 & 3.582 & $2.859^{[b]}$ & $4.582^{[b]}$ & $4.078^{[b]}$ & & & \\
\hline & B19' & 2.8801 & 4.5792 & 4.0321 & $2.898^{[\mathrm{c}]}$ & $4.108^{[c]}$ & $4.646^{[\mathrm{c}]}$ & & & \\
\hline \multirow[t]{2}{*}{ TiPd } & B2 & 3.1263 & & & $3.191^{[\mathrm{a}]}$ & & & $3.18^{[\mathrm{a}]}$ & & \\
\hline & B19 & 2.7030 & 4.6010 & 4.3780 & $2.79^{[\mathrm{b}]}$ & $4.81^{[b]}$ & $4.52^{[b]}$ & 2.81 & 4.89 & 4.52 \\
\hline \multirow[t]{2}{*}{ TiP } & B2 & 3.1374 & & & $3.205^{[\mathrm{a}]}$ & & & $3.192^{[\mathrm{a}]}$ & & \\
\hline & B19 & 2.6464 & 4.5476 & 4.2843 & $2.81^{[\mathrm{b}]}$ & $4.83^{[\mathrm{b}]}$ & $4.55^{[\mathrm{b}]}$ & $2.76^{[\mathrm{a}]}$ & 4.84 & 4.59 \\
\hline \multirow[t]{2}{*}{$\mathrm{TiCu}$} & B2 & 3.0275 & & & $3.07^{[\mathrm{a}]}$ & & & & & \\
\hline & B19 & 2.8966 & 4.6427 & 4.1320 & & & & & & \\
\hline
\end{tabular}

${ }^{[a]}$ Reference [9]; ${ }^{[b]}$ Reference [10]; ${ }^{[c]}$ Reference [11]. 

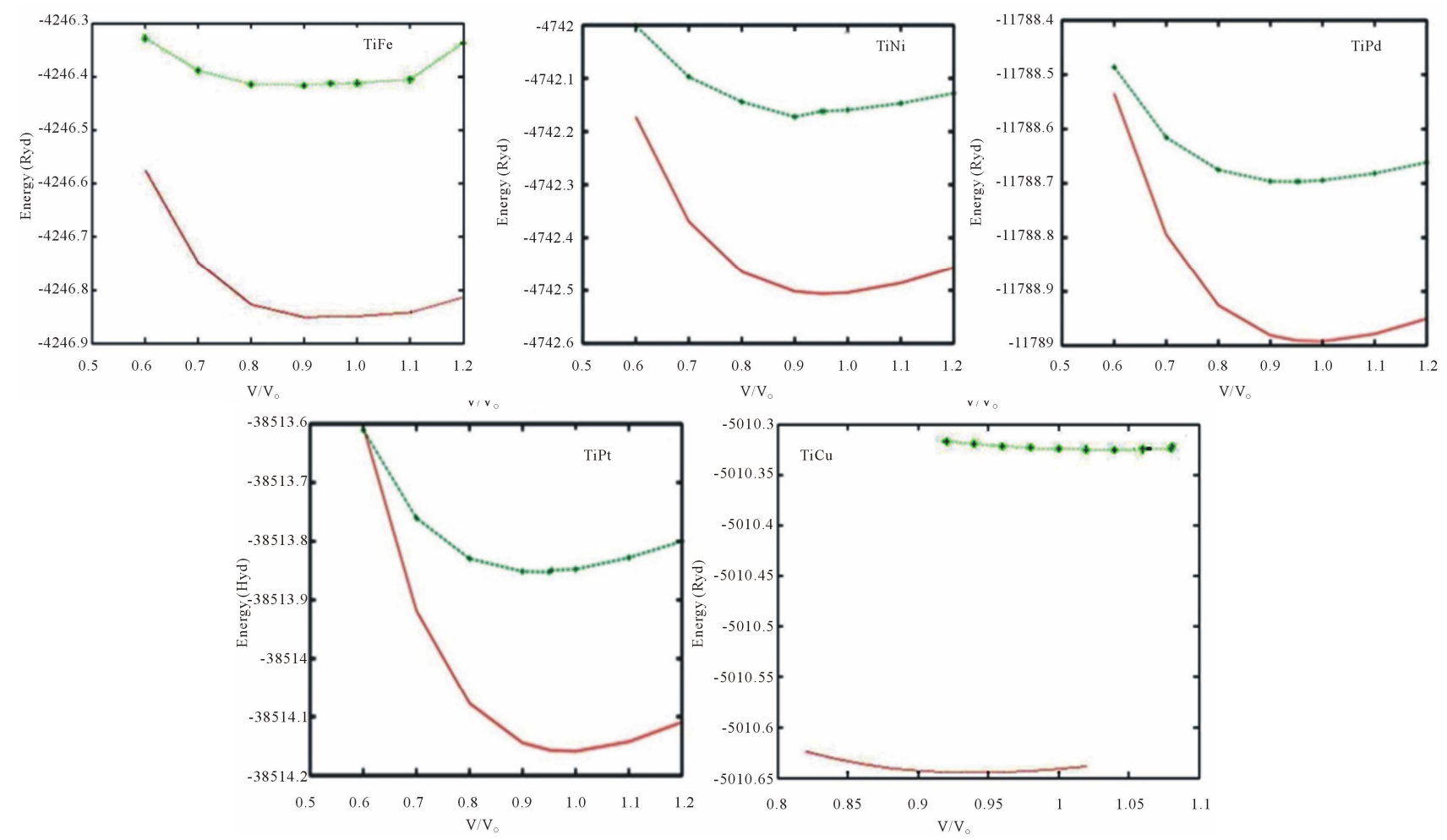

Figure 2. Total energy as a function of volume for $\mathrm{TiX}(\mathrm{X}=\mathrm{Fe}, \mathrm{Ni}, \mathrm{Pd}, \mathrm{Pt}$ and $\mathrm{Cu})$ alloys Continuous line indicate $\mathrm{B} 2$ structure and line with points indicate B19'/B19 structure.

and this is partly ascribed to the local density approximation (LDA) used in the calculations. To minimize the deviations, it is argued that the zero point vibrations have to be included in the calculation [12].

The total energy curves of TiX (X $=$ Fe, Ni, Pd Pt and $\mathrm{Cu})$ alloys in B2 and (B19/B19') phases, as seen in Figure 2 show that these alloys are stable in B2 structure [13] though the energy difference between the two is very small of the order of $0.2502 \mathrm{Ry} / \mathrm{F} . \mathrm{u}$.

\section{Band Structure and Density of State Studies on TiX (X = Fe, Ni, Pd, Pt and $\mathrm{Cu})$ Alloys}

The correlation of structural stability with electronic structure is performed using band structure calculations [14]. The band structures of TiX (X = Fe, Ni, Pd, Pt and $\mathrm{Cu}$ ) alloys have the same generic nature in B2 and B19 structures respectively. They are plotted along high symmetry lines; Figures 3(a) and 3(b) show the band structures of TiX alloys in both phases for several symmetry directions in k-space. The (B19/B19') structure of TiX alloys possesses lower symmetry leading to splitting of degenerate bands in the interior of brillouin zone as seen in Figure 3(b). The size of the brillouin zone is twice as big as B2 structure since it possesses four atoms per unit cell. Hence the band structure of (B19/B19') phase has complicated brillouin zone compared to B2.

The band structure of TiNi in B2 structure is shown in Figure 3(a). The s-orbitals of $\mathrm{Ti}$ and $\mathrm{Ni}$ sites around -8 $\mathrm{eV}$ are the lowest lying valence bands and do not contribute much in deciding the properties of these alloys. The top most valence band below $\mathrm{E}_{\mathrm{F}}$ between $-4 \mathrm{eV}$ and $-2 \mathrm{eV}$ are due to Ti-d states followed by Ni-d states. Below them, the contribution from Ni-p state predominates.

The band dispersions of (B19/B19') phase have similar generic nature as B2 at more bound states as seen in Figure 3(b), yet there are significant differences that can be detected at higher energies near the Fermi level $\mathrm{E}_{\mathrm{F}}$.

This is reflected in the corresponding density of states (DOS) curve there by influencing various physical properties such as susceptibilities and optical conductivities in both phases [15].

The widths of the valence band for all alloys are tabulated in Table 3. We observe the width of the band to be narrower for (B19/B19') phase compared to B2. Hence the interactions between $\mathrm{Ti}$ and $\mathrm{X}(\mathrm{X}=\mathrm{Fe}, \mathrm{Ni}, \mathrm{Pd}, \mathrm{Pt}$ and $\mathrm{Cu})$ atoms are much stronger in (B19/B19') phase compared to B2, which is also reflected in their corresponding DOS curves [15].

In both phases TiPt possess wider bandwidth compared to all other $\mathrm{TiX}(\mathrm{X}=\mathrm{Fe}, \mathrm{Ni}, \mathrm{Pd}$ and $\mathrm{Cu})$ alloys. The higher localization of $\mathrm{Pt}$ atom towards the bound 

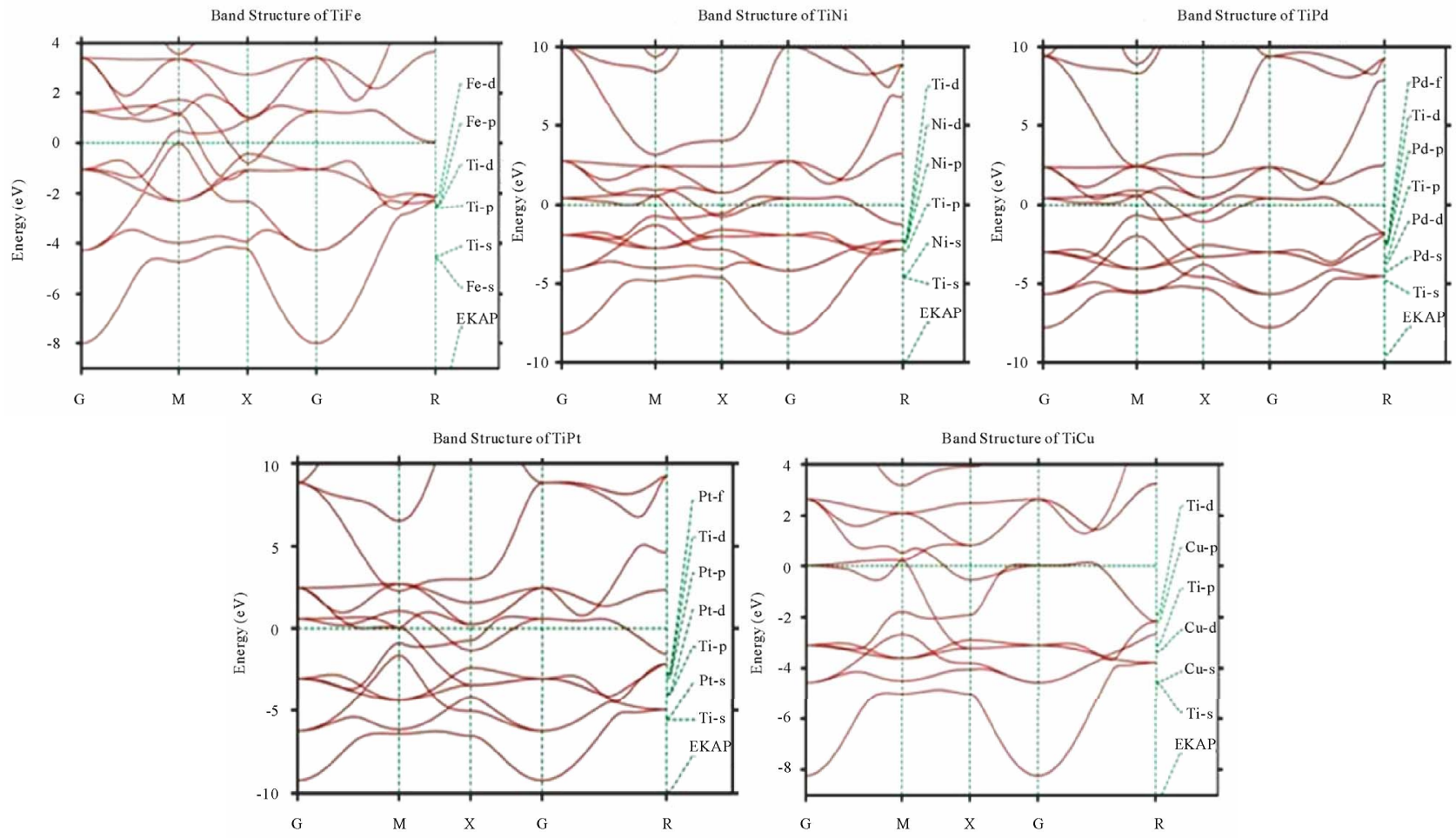

(a)
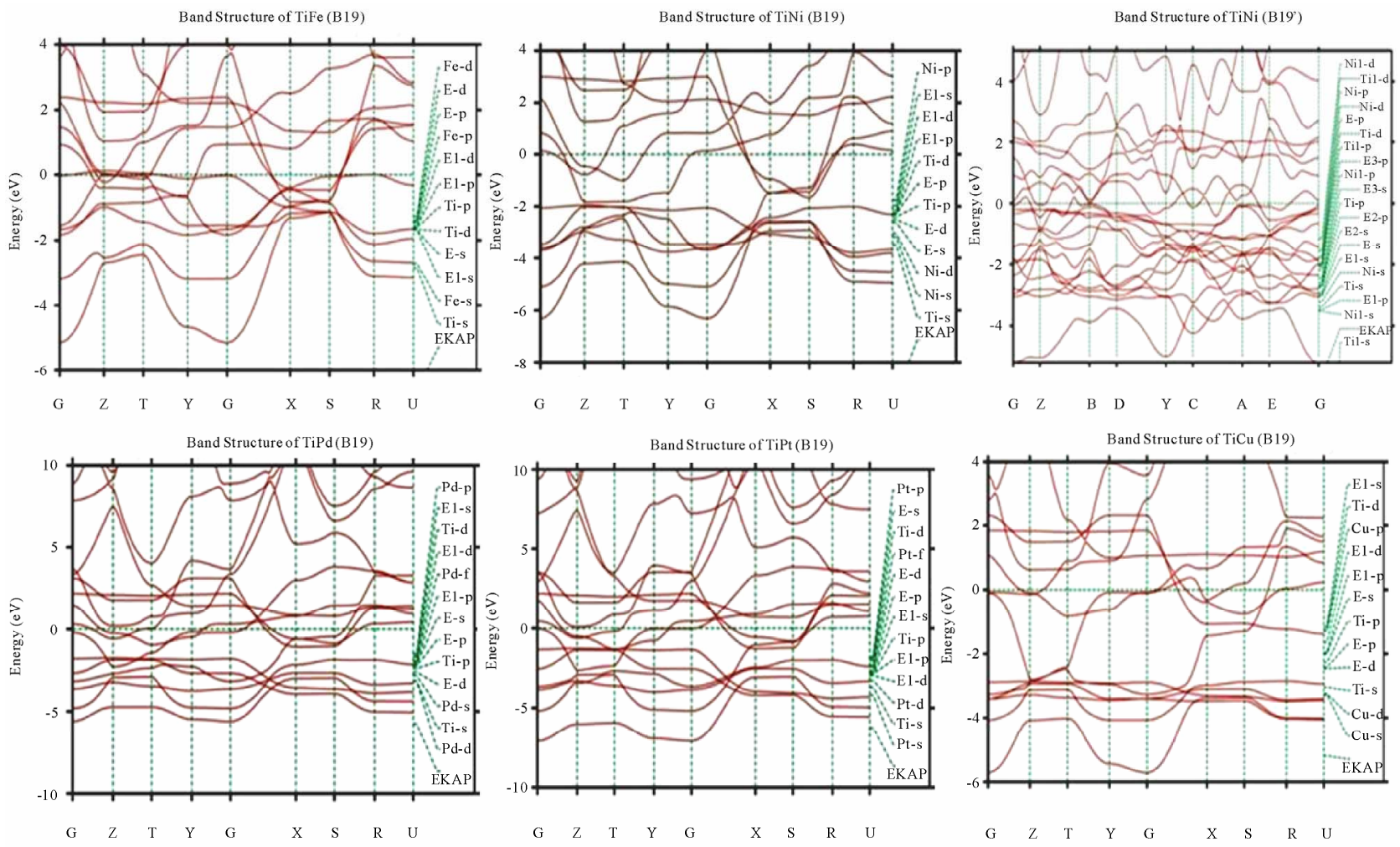

(b)

Figure 3. (a) Band structure of $\mathrm{TiX}(\mathrm{X}=\mathrm{Fe}, \mathrm{Ni}, \mathrm{Pd}, \mathrm{Pt}$ and $\mathrm{Cu})$ in $\mathrm{B} 2$ phase at $\mathrm{V} / \mathrm{V}_{\mathbf{0}}=1$; (b) Band structure of $\mathrm{TiX}(\mathrm{X}=\mathrm{Fe}, \mathrm{Ni}$, $P d, P t$ and $\mathrm{Cu}$ ) in $\mathrm{B} 19$ phase at $\mathrm{V} / \mathrm{V}_{0}=1$. 
state in comparison to other $\mathrm{X}(\mathrm{X}=\mathrm{Fe}, \mathrm{Ni}, \mathrm{Pd}$, and $\mathrm{Cu})$ atoms results in decrease in overlap of bands between $\mathrm{Ti}$ and Pt. This weakens the interaction between the two, and consequently the strength of the covalent bonding between them is decreased.

\section{Density of States}

To study the phase stability at microscopic level, the DOS are calculated for the $\mathrm{TiX}(\mathrm{X}=\mathrm{Fe}, \mathrm{Ni}, \mathrm{Pd}$, and $\mathrm{Cu})$ alloys at their equilibrium volumes and are plotted using linear tetrahedron method. In present study, the double peak structure is the most typical two peak structure of the total DOS curve which is shown in Figures 4(a) and 4(b).

The DOS curves for B19/B19' structures are similar in nature to that of the B2. Due to lower symmetry the DOS peaks of the B19 and B19' structures tend to be broader than B2. There are some changes noticed in the lower portion of the DOS curves of B19/B19' structure at a range of $\pm 1.5 \mathrm{eV}$ around Fermi. From Figures 4(a) and 4(b) we observe the dividing dip of the DOS in B2 structure at about $-1.5 \mathrm{eV}$ around Fermi becomes less conspicuous in B19 structures. In B19' structure, near the Fermi level within a range of $\pm 1.5 \mathrm{eV}$ there is an upward shift of the dip of the DOS curve.

The DOS curve of TiFe alloy in both phases is found to be in good agreement with the reported results of $\mathrm{Y}$. Ye et al. The typical feature of the total DOS curve of TiFe in B2 phase is the presence of pseudo gap. Two mechanisms were proposed for the formation of pseudo gap in the binary alloys [16]. One is of ionic origin, and other is owing to hybridization effects. As the electro negativity difference between $\mathrm{Ti}$ and $\mathrm{X}$ is low, the ionicity does not play a major role on bonding behavior of these compounds. Consequently the pseudo gap present in TiFe alloys is believed to be due to covalent hybridization between $\mathrm{Ti}$ and $\mathrm{Fe}$ atoms. Such a strong hybridization gives not only an important mixing between the states of conduction bands but also leads to a separation of bonding states creating a pseudo gap.

In the present work we observe that in B2 structure the shape of the DOS curve of TiNi is similar to TiFe. For both alloys the $E_{F}$ falls on a dip as shown in Figure 4(a). It is well known fact that if the Fermi level $E_{F}$ falls on the dip, the corresponding structure may be regarded as a save energy system as compared with one whose Fermi level $E_{F}$ does not fall on a dip. Therefore TiFe and TiNi alloys are more stable than other transition metals $\mathrm{Pd}, \mathrm{Pt}$ and noble metal $\mathrm{Cu}$. On going from TiPd, TiPt and $\mathrm{TiCu}$ the B2 structure becomes relatively less stable, as the Fermi level $\mathrm{E}_{\mathrm{F}}$ shifts from the dip towards higher peaks of the DOS [17]. This is accounted by the increase in valence electrons which will tend to shift the Fermi level
$\mathrm{E}_{\mathrm{F}}$ from the dip towards the anti-bonding states. From Figure 4(b) similar dip is observed for TiPd, wherein the Fermi level $\mathrm{E}_{\mathrm{F}}$ falls on the dip. Hence TiNi and TiFe in B2 structure and TiFe and TiPd in B19 structure have low $\mathrm{N}\left(\mathrm{E}_{\mathrm{F}}\right)$ values at Fermi and are considered to be most stable structures. However the stability of TiPd in B19 contradicts the inference for the total energy calculations shown in Figure 2. As the energy of TiPd at Fermi is lower for B2 $(-0.0523 \mathrm{eV})$ when compared to B19 $(0.0271 \mathrm{eV})$ structure, TiPd can be considered to be stable in B2 structure. This is in line with the results reported by Ravindran et al. [17] in the case of $\mathrm{Ni}_{3} \mathrm{Al}$ and $\mathrm{Ni}_{3} \mathrm{Al}_{0.75} \mathrm{Nb}_{0.25}$.

As the electrons around $\mathrm{E}_{\mathrm{F}}$ play an important role in deciding the electronic, structural and mechanical properties of the alloys, we carry out the investigations on the electronic structure histogram using the projected DOS of TiX alloys. General nature of the DOS histograms of all $\mathrm{TiX}(\mathrm{X}=\mathrm{Fe}, \mathrm{Ni}, \mathrm{Pd}, \mathrm{Pt}$ and $\mathrm{Cu})$ alloys are observed to be similar of which the DOS histogram of TiNi alloy is shown in Figure 4(c). consists of three parts 1) the peak present in the lower energy part of the DOS curve is mainly due to the localized or tightly bound s-electrons of $\mathrm{Ni}$ and $\mathrm{Ti}$ atoms; 2) the bonding sates of Ti-d and Ni-p orbitals are near (to the left of) the Fermi level $E_{F} ; 3$ ) the DOS curve due to anti-bonding states. It is found that Ti-s state and Ni-s-state electrons in TiX alloy are localized and its effect in bonding is very small. Thus the electrons from Ti-d and Ni-d, Ni-p states predominately contribute to the density of states at the Fermi level $\mathrm{E}_{\mathrm{F}}$.

In order to explore the role of $\mathrm{X}(\mathrm{X}=\mathrm{Fe}, \mathrm{Ni}, \mathrm{Pd}, \mathrm{Pt}$ and $\mathrm{Cu}$ ) atoms in the Ti-based alloys we compare the d-partial DOS curves of these alloys as shown in Figures 4(d) and 4(e). We observe that the d-states of Ti atom at Fermi shows a dominance compared to $\mathrm{X}(\mathrm{X}=\mathrm{Ni}, \mathrm{Pd}, \mathrm{Pt}$, $\mathrm{Cu}$ ) atoms. The XPS studies by Shabaloskaya et al. [18] show that as elemental $\mathrm{X}$ atoms combine with Ti atom to form $\mathrm{TiX}(\mathrm{X}=\mathrm{Ni}, \mathrm{Pd}, \mathrm{Pt}, \mathrm{Cu})$ compound, it results in enhancement of localization of d-electron of $\mathrm{X}$ atoms towards bound state. Hence the intensity of the $d$-band of $\mathrm{X}$ atom in $\mathrm{TiX}(\mathrm{X}=\mathrm{Ni}, \mathrm{Pd}, \mathrm{Pt}, \mathrm{Cu})$ alloys considerably decreases at Fermi and that of Ti atom increases. However in case of TiFe alloy, we observe the d-states of $\mathrm{Fe}$ atom to dominate that of $\mathrm{Ti}$ at Fermi. This is because as elemental Fe forms TiFe compound on combination with $\mathrm{Ti}$ atom, the position of $\mathrm{d}$-band peaks of $\mathrm{Fe}$ atom does not change [19], (i.e.) (the $\mathrm{Fe}$ atom does not undergo much localization as other $\mathrm{X}(\mathrm{X}=\mathrm{Ni}, \mathrm{Pd}, \mathrm{Pt}, \mathrm{Cu})$ atoms $)$. Thus the d-band of $\mathrm{Fe}$ atom shows much dominance at Fermi when compared to that of d-band of Ti.

This is also well supported by the DOS values of TiX $(\mathrm{X}=\mathrm{Ni}, \mathrm{Pd}, \mathrm{Pt}, \mathrm{Cu})$ alloys at $\mathrm{E}_{\mathrm{F}}$ which are tabulated in Table 2. From Table 2 in both B2 and B19 structure, we 

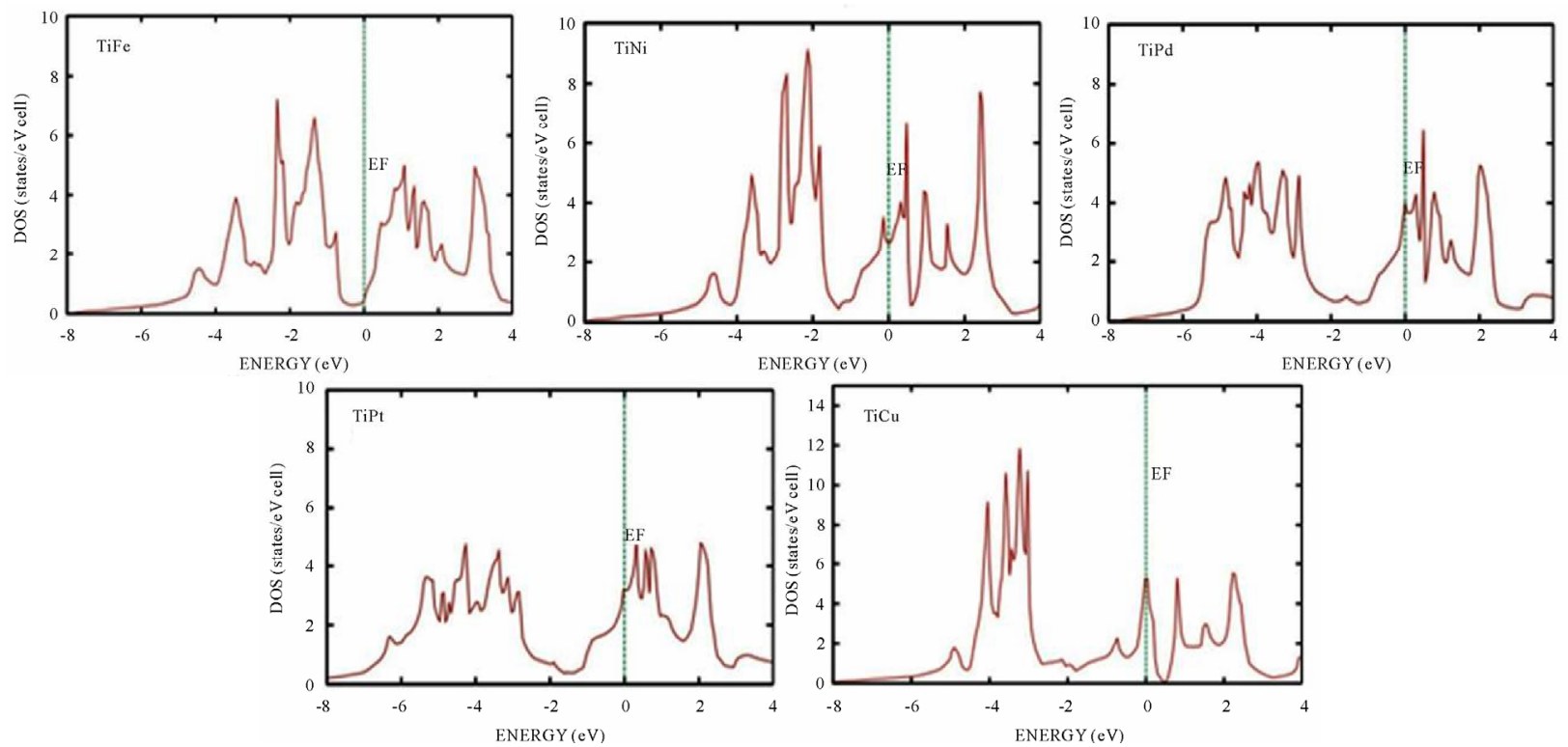

(a)
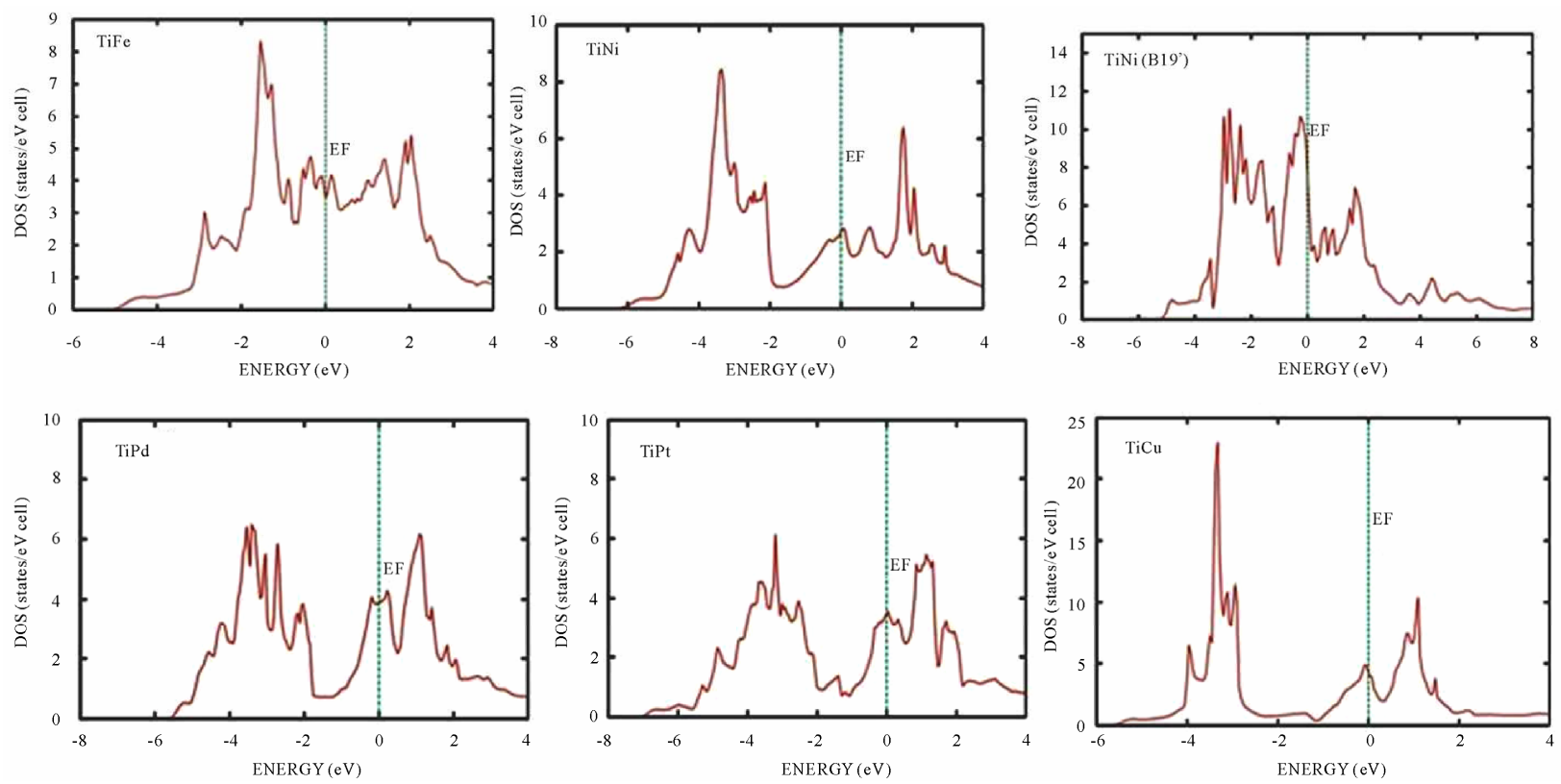

(b)
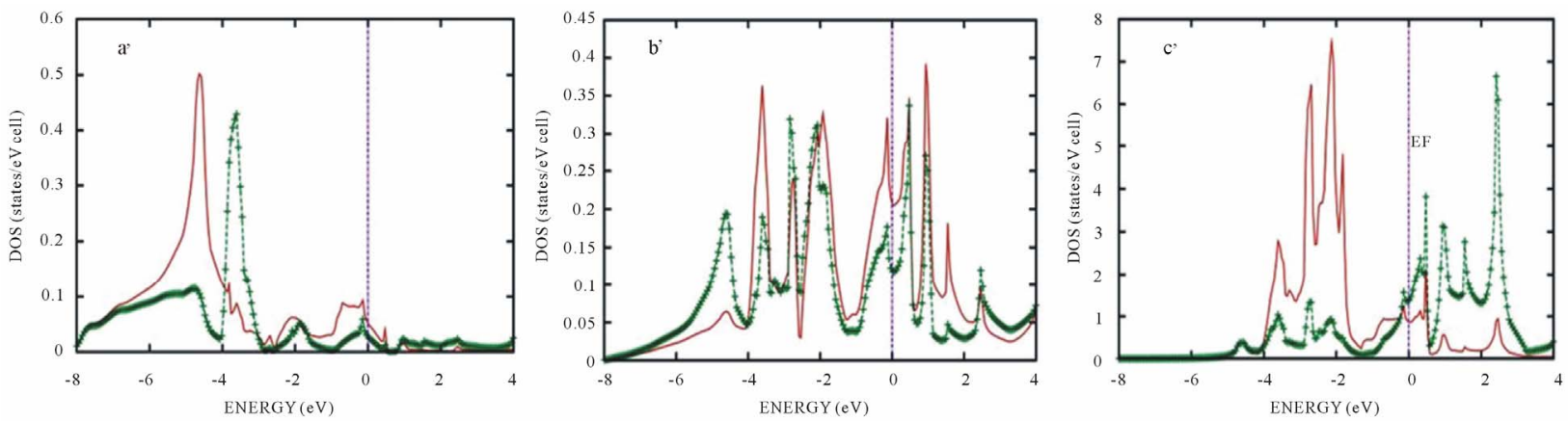

(c) 

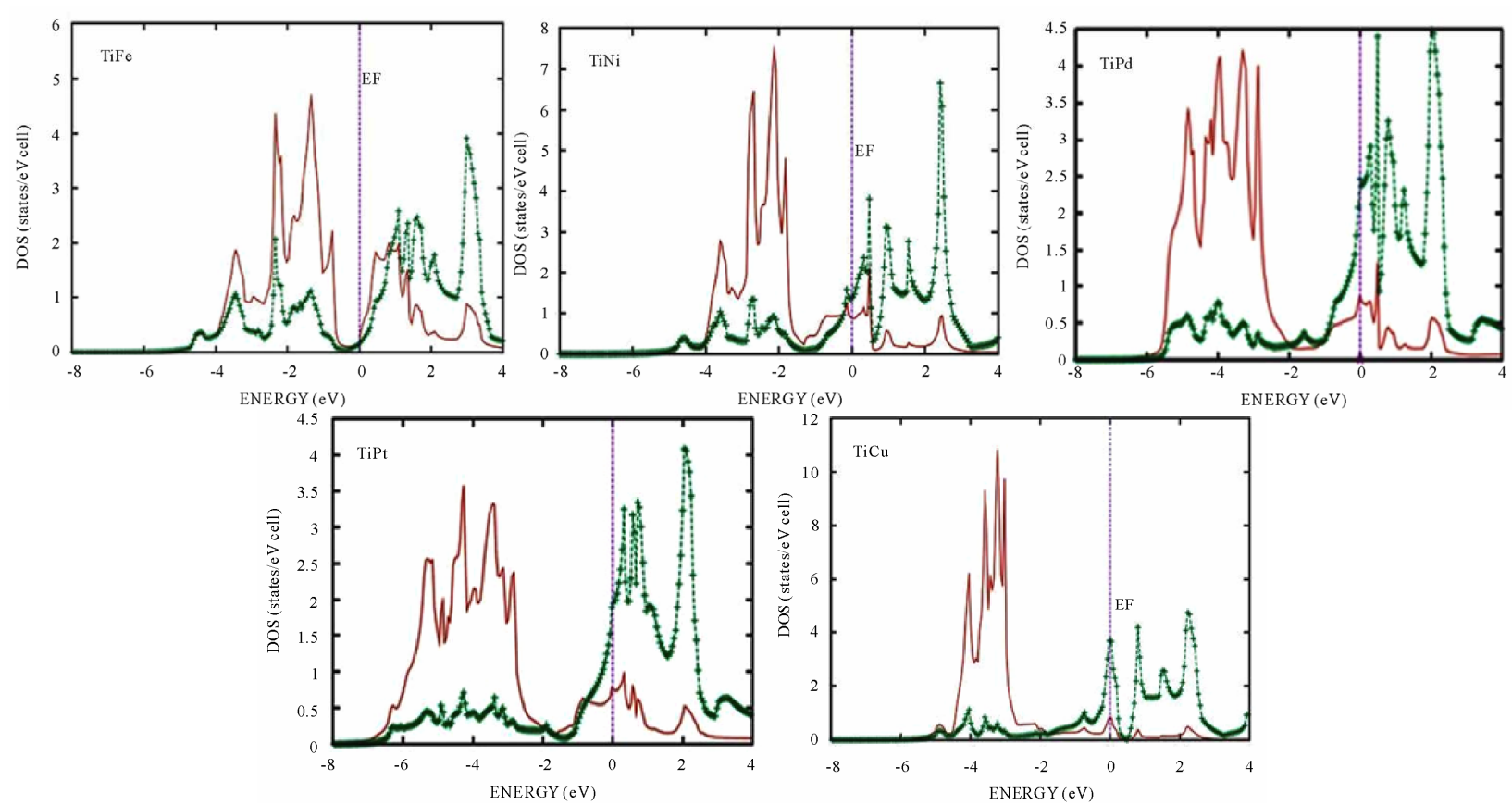

(d)
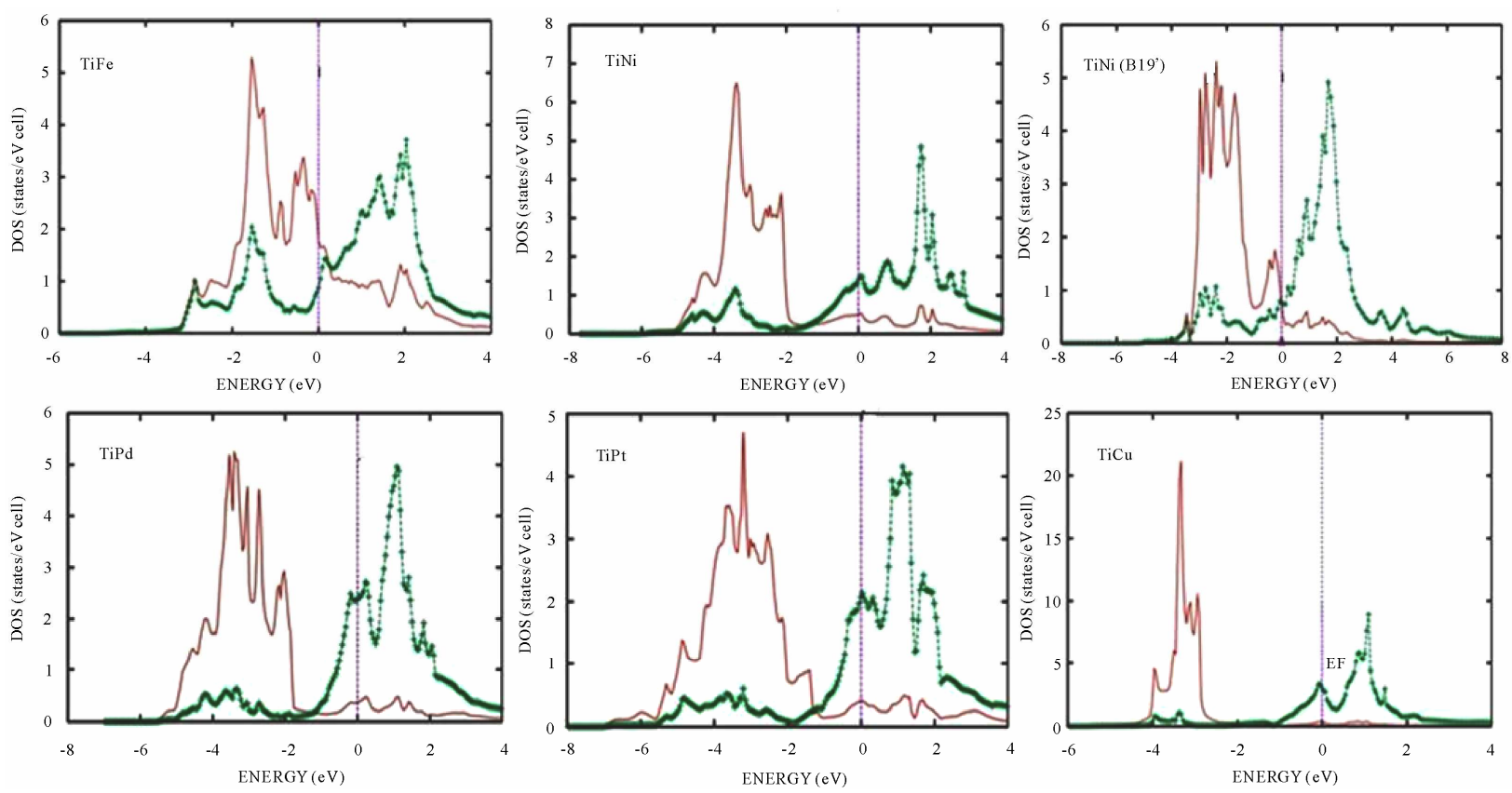

(e)

Figure 4. (a) Total DOS structure of TiX $(\mathrm{X}=\mathrm{Fe}, \mathrm{Ni}, \mathrm{Pd}, \mathrm{Pt}$ and $\mathrm{Cu})$ in B2 Phase; (b) total DOS structure of TiX (X= Fe, Ni, Pd, Pt and Cu) in B19 Phase; (c) (a') s-Partial DOS (b') p-Partial DOS (c') d-Partial DOS of TiNi in B2 phase. Line with points indicate Ti atom and continuous line indicate Ni atom; (d) d-Partial DOS of TiX (X $=\mathrm{Fe}, \mathrm{Ni}, \mathrm{Pd}, \mathrm{Pt}$ and $\mathrm{Cu})$ alloys in B2 phase. Line with points indicate Ti atom and continuous line indicates $\mathrm{X}$ atoms; (e) d-Partial DOS of TiX (X $=\mathrm{Fe}, \mathrm{Ni}$, Pd, $\mathrm{Pt}$ and $\mathrm{Cu}$ ) alloys in $\mathrm{B} 19$ phase. Line with points indicate $\mathrm{Ti}$ atom and continuous line indicates $\mathrm{X}$ atoms.

observe the d-DOS value of Ti at $\mathrm{E}_{\mathrm{F}}$ in general increases from $\mathrm{TiFe}$ to $\mathrm{TiCu}$ along which the stability of phases decreases. The increase in degeneracy of the d-states of
Ti at Fermi level $E_{F}$ decreases the phase stability as suggested by Wang et al. [20]. Except for Fe atom, the dDOS contribution of $\mathrm{X}$ atom to DOS at Fermi level $\mathrm{E}_{\mathrm{F}}$, is 
Table 2. The DOS value at the $\mathrm{E}_{\mathrm{F}}$ in $\mathrm{TiX}(\mathrm{X}=\mathrm{Fe}, \mathrm{Ni}, \mathrm{Pd}, \mathrm{Pt}$ and $\mathrm{Cu})$ alloys.

\begin{tabular}{cccccccccccccc}
\hline ALLOYS & \multicolumn{2}{c}{ TiFe } & \multicolumn{2}{c}{ TiNi } & \multicolumn{3}{c}{ TiPd } & \multicolumn{2}{c}{ TiPt } & \multicolumn{3}{c}{ TiCu } \\
\hline PHASE & B2 & B19 & B2 & B19 & B19 & B2 & B19 & B2 & B19 & B2 & B19 \\
$\mathrm{N}_{\mathrm{d}}\left(\mathrm{E}_{\mathrm{f}}\right)$ of Ti & 0.1841 & 0.8607 & 1.353 & 1.9886 & 0.7651 & 2.4000 & 2.1904 & 1.9230 & 2.1428 & 3.5596 & 2.9885 \\
$\mathrm{~N}_{\mathrm{d}}\left(\mathrm{E}_{\mathrm{f}}\right)$ of X & 0.2957 & 1.8116 & 0.882 & 0.7272 & 0.6262 & 0.8285 & 0.3714 & 0.7500 & 0.4000 & 0.8217 & 0.2952 \\
$\mathrm{~N}_{\mathrm{p}}\left(\mathrm{E}_{\mathrm{f}}\right)$ of Ti & 0.0377 & 0.1435 & 0.117 & 0.1181 & 0.0198 & 0.1950 & 0.1795 & 0.1034 & 0.1568 & 0.3397 & 0.1551 \\
$\mathrm{~N}_{\mathrm{p}}\left(\mathrm{E}_{\mathrm{f}}\right)$ of X & 0.0442 & 0.1982 & 0.205 & 0.1948 & 0.0982 & 0.1971 & 0.2431 & 0.2571 & 0.2857 & 0.3586 & 0.2665 \\
$\mathrm{~N}_{\mathrm{s}}\left(\mathrm{E}_{\mathrm{f}}\right)$ of Ti & 0.0032 & 0.0781 & 0.029 & 0.0925 & 0.0188 & 0.0558 & 0.1121 & 0.0465 & 0.1037 & 0.0174 & 0.0958 \\
$\mathrm{~N}_{\mathrm{s}}\left(\mathrm{E}_{\mathrm{f}}\right)$ of X & 0.0045 & 0.1040 & 0.047 & 0.1318 & 0.0256 & 0.0941 & 0.0636 & 0.0655 & 0.0409 & 0.0174 & 0.0443 \\
$\mathrm{~N}_{\mathrm{T}}\left(\mathrm{E}_{\mathrm{f}}\right)$ of Ti & 0.2161 & 1.1177 & 1.470 & 1.9318 & 0.7810 & 2.6300 & 2.4761 & 2.0769 & 2.3714 & 3.9669 & 3.3383 \\
$\mathrm{~N}_{\mathrm{T}}\left(\mathrm{E}_{\mathrm{f}}\right)$ of X & 0.3135 & 2.0951 & 1.117 & 1.0455 & 0.7555 & 1.2280 & 0.6984 & 1.1363 & 0.7619 & 1.1467 & 0.6021 \\
$\mathrm{~N}_{\mathrm{T}}\left(\mathrm{E}_{\mathrm{f}}\right)$ of TiX & 0.4427 & 3.4932 & 2.588 & 3.4285 & 3.9149 & 3.8636 & 3.6000 & 3.2000 & 3.5600 & 5.0767 & 4.3034 \\
\hline
\end{tabular}

relatively small when compared to Ti. We observe Ti-d state is virtually twice as high as the corresponding state of $\mathrm{X}$ atom, resulting in weakening of $\mathrm{d}_{\mathrm{Ti}_{\mathrm{i}}}-\mathrm{d}_{\mathrm{X}}$ directional bond between them. The main part of the bonding state of d-electrons of $\mathrm{X}$ site gradually move towards the bottom of the valence band while the anti-bonding state of d-electrons at $\mathrm{Ti}$ site becomes gradually strong, thereby weakening the $\mathrm{d}_{\mathrm{T}^{2}}-\mathrm{d}_{\mathrm{X}}$ directional bond between them.

Thus as the atomic number of $\mathrm{X}(\mathrm{X}=\mathrm{Fe}, \mathrm{Ni}, \mathrm{Pd}, \mathrm{Pt}$, $\mathrm{Cu}$ ) atom increases, its d-state in both B2 and B19 phases become more localized, the maximum of d-bands shifts towards the bottom of the valence band, and the X contribution to the density of states (DOS) at the Fermi level $\mathrm{N}\left(\mathrm{E}_{\mathrm{F}}\right)$, degrades (Table 2). While the d electron contribution of $\mathrm{X}$ to the DOS at $\mathrm{E}_{\mathrm{F}}$ decreases, the $\mathrm{d}$ electron contribution of Ti increases to such an extent that in TiPd and $\mathrm{TiCu}$, the $\mathrm{X}$ contribution to $\mathrm{N}\left(\mathrm{E}_{\mathrm{F}}\right)$ is almost negligible. Hence the d-DOS localization accompanied by a spatial localization of $d$ electrons of $\mathrm{X}(\mathrm{X}=\mathrm{Fe}, \mathrm{Ni}, \mathrm{Pd}, \mathrm{Pt}$, $\mathrm{Cu}$ ) atom results in weakening of the $\mathrm{d}-\mathrm{d}$ covalent bonds between the alloy components thus, destabilizing the phase.Similarly from Table 2 we observe the $p$ contribution of $\mathrm{X}$ atom to DOS at $\mathrm{E}_{\mathrm{F}}$ are relatively smaller than $\mathrm{d}$ contribution of X. Hence the p-d hybridisation will be less pronounced for all these alloys.

In order to compare the nature of hybridisation in each alloy we have plotted graphs between the differnce in $\mathrm{d}$ DOS of Ti and X with d electrons of X atoms, and difference in $\mathrm{d}$ DOS of Ti and $\mathrm{p}$ of $\mathrm{X}$ atom with $\mathrm{d}$ electron of $X$ atoms as shown in Figures 5 and 6 In On comparing Figures 5 and $\mathbf{6}$ we observe that both hybridisations follow the similar trend. The $\mathrm{d}-\mathrm{d}$ and $\mathrm{p}-\mathrm{d}$ hybridisations are well pronounced for TiFe in B2 and B19 structure.

In case of TiNi d-d hybridization in B19' structure dominates. For TiPd and TiPt p-d hybridization in B19

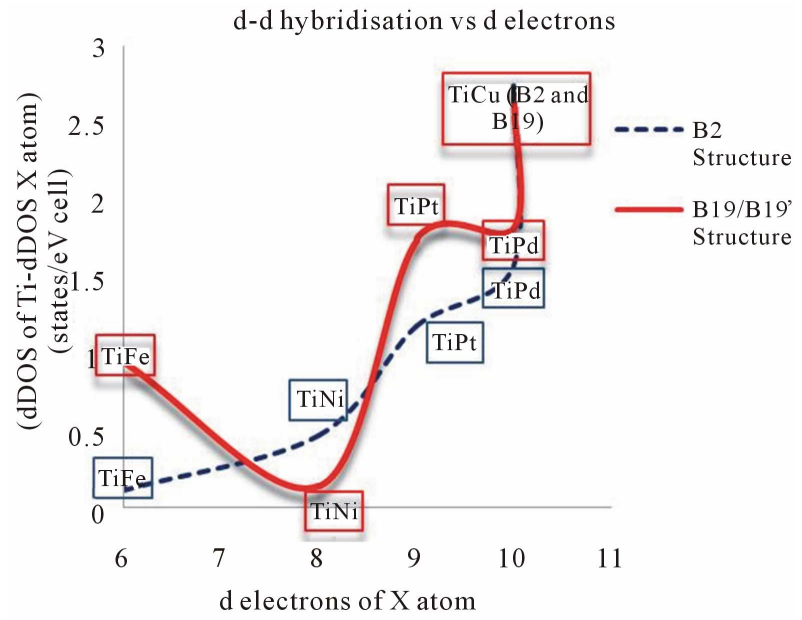

Figure 5. d-d hybridation of TiX $(\mathrm{X}=\mathrm{Fe}, \mathrm{Ni}, \mathrm{Pd}$, Pt and $\mathrm{Cu})$ in $\mathrm{B} 2$ and B19/B19' phase.

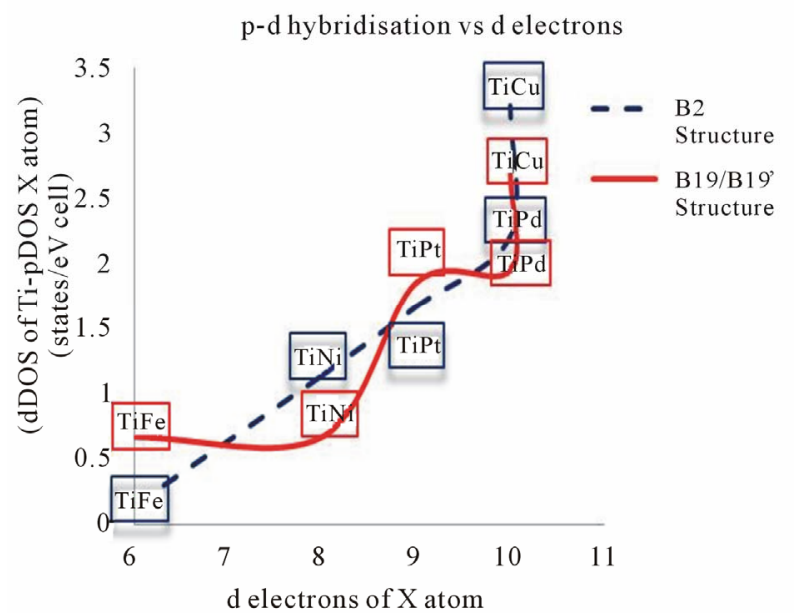

Figure 6. p-d hybridation of $\mathrm{TiX}(\mathrm{X}=\mathrm{Fe}, \mathrm{Ni}, \mathrm{Pd}, \mathrm{Pt}$ and $\mathrm{Cu})$ in $\mathrm{B} 2$ and B19/B19' phase. 
structure is much pronounced than d-d hybridization. And both the hybridizations are very less pronounced in $\mathrm{TiCu}$.

\section{Cohesive Energy and Heat of Formation}

The cohesive energy of a material is a fundamental property which has long been the subject of theoretical and computational approaches. The chemical bonding is a mixture between covalent, ionic, and metallic bonding and therefore the cohesive energy cannot be determined reliably from simple models. Thus, first principles calculations based on density functional theory (DFT) have become a useful tool to determine the cohesive energy of the solids. In this connection, the cohesive energy of TiX ( $\mathrm{X}=\mathrm{Fe}, \mathrm{Ni}, \mathrm{Pd}, \mathrm{Pt}$ and $\mathrm{Cu}$ ) alloy is calculated by using the expression

$$
\mathrm{TiX}_{\text {coh }}^{\mathrm{AB}}=\left[\mathrm{Ti}_{\text {atom }}^{\mathrm{A}}+\mathrm{X}_{\mathrm{atom}}^{\mathrm{B}}\right]-\mathrm{TiX}_{\text {total }}^{\mathrm{AB}}
$$

$\mathrm{TiX}_{\text {total }}^{\mathrm{AB}}$ refers to the total energy of the TiX alloy at equilibrium lattice constants and $\mathrm{Ti}_{\text {atom }}^{\mathrm{A}}$ and $\mathrm{X}_{\text {atom }}^{\mathrm{B}}$ are the atomic energies of the pure $\mathrm{Ti}$ and $\mathrm{X}(\mathrm{X}=\mathrm{Fe}, \mathrm{Ni}, \mathrm{Pd}$, $\mathrm{Pt}$ and $\mathrm{Cu}$ ) constituents calculated semi-relativistically. To determine the heat of formation, we have first calculated the total energy of Ti element and $\mathrm{X}(\mathrm{X}=\mathrm{Fe}, \mathrm{Ni}$, $\mathrm{Pd}, \mathrm{Pt}$ and $\mathrm{Cu}$ ) corresponding to their respective equilibrium lattice parameters. The free energy of formation or the heat of formation $(\Delta \mathrm{H})$ can be obtained from the following relation:

$$
(\Delta \mathrm{H})^{\mathrm{AB}}=\mathrm{TiX}_{\text {total }}^{\mathrm{AB}}-\left[\mathrm{Ti}_{\text {solid }}^{\mathrm{A}}+\mathrm{X}_{\text {solid }}^{\mathrm{B}}\right]
$$

where $\mathrm{TiX}_{\text {total }}^{\mathrm{AB}}$ refers to the total energy of $\operatorname{TiX}(\mathrm{X}=\mathrm{Fe}$,
$\mathrm{Ni}, \mathrm{Pd}, \mathrm{Pt}$ and $\mathrm{Cu}$ ) alloy at equilibrium lattice constants and $\mathrm{Ti}_{\text {solid }}^{\mathrm{A}}$ and $\mathrm{X}_{\text {solid }}^{\mathrm{B}}$ is the total energy of the pure elemental constituents.

The calculated values of the cohesive energies and heat of formation of all systems are given in Table 3. The systematic errors in total energy due to the ASA are cancelled due to the nature of the formula of differences in total energy leading to a reasonably accurate formation of energy.

The cohesive energies of the alloys are slightly lower in (B19/B19') phase compared to B2 phase except for TiNi. This indicates that atoms in $\mathrm{B} 2$ phase are strongly bound with better mechanical strength than (B19/B19') phase. In the case of TiNi the cohesive energy is much higher in B19' phase compared to B2 phase indicating that bonding effect is much stronger in B19' phase compared to $\mathrm{B} 2$ phase. This is due to strong $\mathrm{d}_{\mathrm{Ti}}-\mathrm{d}_{\mathrm{X}}$ directional bonding between $\mathrm{Ti}$ and $\mathrm{Ni}$ atom which can also be seen from Table 2. It is observed from Figure 7 that the cohesive energies of $5 \mathrm{~d}$ transition series is higher compared to $3 \mathrm{~d}$ series which is due to higher localization of $\mathrm{Pd}$ and $\mathrm{Pt}$ atom compared to $3 \mathrm{~d}$ elements such as $\mathrm{Fe}, \mathrm{Ni}$ and $\mathrm{Cu}$. This confirms the experimental studies, that $5 \mathrm{~d}$ elements of larger cohesive energies have higher melting point [21].

From Table 3, the study on heat of formation show that the ordering energy values except for TiFe are much higher in (B19/B19') phase compared to B2 phase which is seen in Figure 8. This is a positive indication of strong directional bonding leading to brittleness in (B19/B19') phase. The present theoretical values of heat of formation

Table 3. The theoretically calculated cohesive energy $\left(E_{\text {coh }}\right.$ in $\left.\mathrm{eV} / \mathrm{F} . u\right)$, heat of formation $(\Delta H$ in $\mathrm{eV})$, bulk modulus $\left(B_{0}\right.$ in Mbar) for TiX (X = Fe, Ni, Pd, Pt and $\mathrm{Cu})$ alloys.

\begin{tabular}{cccccccc}
\hline Alloy & Type & $\mathrm{E}_{\text {coh }}(\mathrm{eV} / \mathrm{F} . \mathrm{u})$ & $-\Delta \mathrm{H}(\mathrm{eV})$ & $\mathrm{B}_{\mathrm{o}}(\mathrm{Mbar})$ & $\mathrm{e} / \mathrm{a}$ & $\mathrm{N}\left(\mathrm{E}_{\mathrm{F}}\right)(\mathrm{eV})$ & Width of the valence band $(\mathrm{eV})$ \\
\hline TiFe & B2 & 1.9955 & 0.3761 & 3.3084 & 6 & 0.4427 & 7.9577 \\
& $\mathrm{~B} 19$ & 1.9953 & 0.3755 & 1.6083 & & 3.4931 & 5.1720 \\
TiNi & B2 & 2.4187 & $0.6400 .66^{[\mathrm{a}]}$ & $2.2984,1.56^{[\mathrm{a}]}$ & 7 & 2.5881 & 8.1818 \\
& B19 & 2.4186 & 0.750 & 1.5891 & 3.4285 & 6.2063 \\
& B19 & 2.8262 & 0.9520 & 1.5603 & 3.9149 & 5.0117 \\
TiPd & B2 & 6.0124 & $1.0330 .92^{[\mathrm{a}]}$ & 2.8446 & 7 & 3.8636 & 7.8409 \\
& B19 & 6.0122 & 2.582 & 3.0112 & & 3.6000 & 5.777 \\
TiPt & B2 & 19.6423 & $1.6301 .49^{[\mathrm{a}]}$ & 2.1717 & 7 & 3.2000 & 9.2045 \\
& B19 & 19.6420 & 1.879 & 3.4499 & & 3.5600 & 7.1379 \\
TiCu & B2 & 2.6187 & 2.2448 & 0.8851 & 7.5 & 5.0784 & 8.2688 \\
& B19 & 2.6185 & 2.2444 & 0.9847 & & 4.3036 & 5.8078 \\
\hline
\end{tabular}

${ }^{\mathrm{a}}$ Reference [3]. 


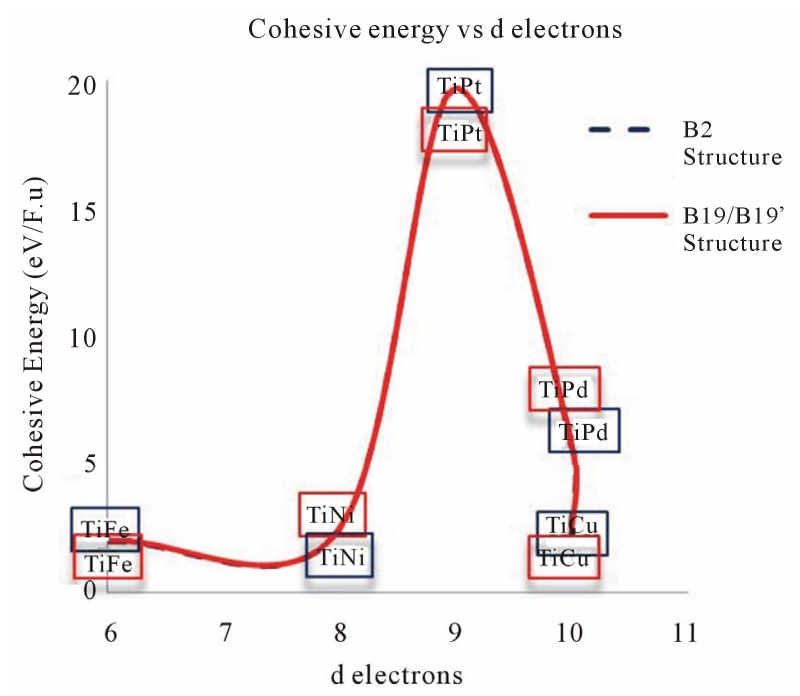

Figure 7. Variation of cohesive energy as function of " $d$ " electrons of $\mathrm{X}$ in $\mathrm{TiX}(\mathrm{X}=\mathrm{Fe}, \mathrm{Ni}, \mathrm{Pd}, \mathrm{Pt}$ and $\mathrm{Cu})$ alloy.

of TiX alloys tend to increase systematically as we go from $3 \mathrm{~d}$ to $4 \mathrm{~d}$ to $5 \mathrm{~d}$ metals [22]. From Figure 8 we observe the heat of formation increases from $\mathrm{TiFe}$ to TiNi and then to TiPd. The TiPd alloy possesses highest heat of formation energy in B19 phase.

\section{Equation of State}

The total energy of TiX (X = Fe, Ni, Pd, Pt and Cu) alloys has been calculated for different reduced and extended volumes and fitted with the sixth order polynomial. From the first derivative of the polynomial the P-V data of TiX $(\mathrm{X}=\mathrm{Fe}, \mathrm{Ni}, \mathrm{Pd}, \mathrm{Pt}$ and $\mathrm{Cu})$ in their stable structures are generated. Vinet et al. have proposed a universal equation of state which is valid for all the classes of solids under compression. The UEOS is expressed as

$$
\mathrm{P}=3 \mathrm{~B}_{0}(1-x) / x 2 \exp [\eta(1-x)]
$$

where $x$ denotes $\left(\mathrm{V} / \mathrm{V}_{\mathrm{o}}\right)^{1 / 3}$ and $\mathrm{B}_{\mathrm{o}}$ refers to the bulk modulus. If one defines $\mathrm{H}(x)=x^{2} \mathrm{P}(x) /[3(1-x)]$, then the $\ln [\mathrm{H}(x)]$ versus $1-x$ curve should be linear and obey the relation

$$
\operatorname{In}[\mathrm{H}(x)] \approx \operatorname{InB}_{\mathrm{o}}+\eta(1-x)
$$

The bulk modulus of TiX alloys in B2 and (B19/B19') structures are given in Table 3 and shown in Figure 9. From the bulk modulus curve, for B19 the $\mathrm{B}_{\mathrm{o}}$ value is found to be maximum for $5 \mathrm{~d}$ TiPt followed by $4 \mathrm{~d}$ TiPd and $3 \mathrm{~d}$ TiNi. Generally, the compounds with high melting temperature $T_{m}$ are expected to have high $B_{o}$ value. The melting temperatures of TiPt, TiPd and TiNi are $1830 \mathrm{~K}, 1673 \mathrm{~K}$ and $1583 \mathrm{~K}$, respectively. Thus, a systematic trend between $\mathrm{B}_{\mathrm{o}}$ and $\mathrm{T}_{\mathrm{m}}$ is observed in B19
Heat of formation vs Structure

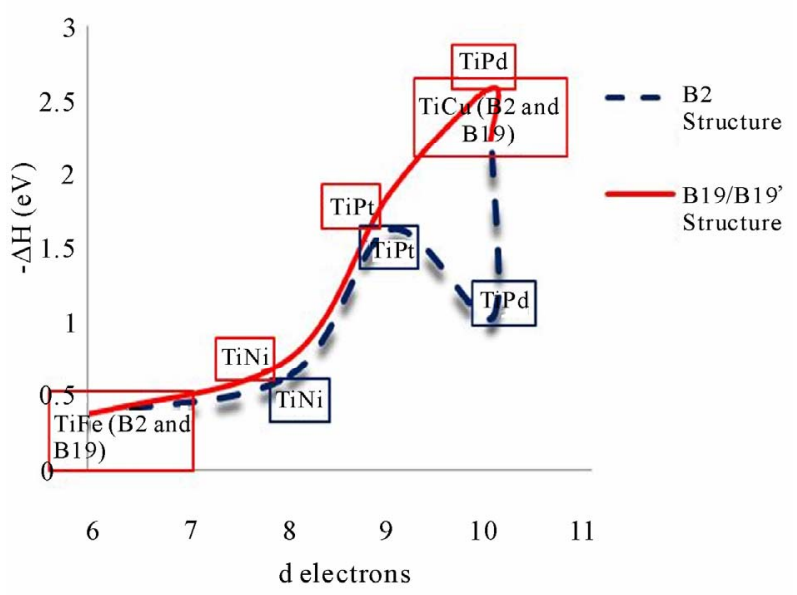

Figure 8. Variation of heat of formation as function of " $d$ " electrons of $\mathrm{X}$ in $\mathrm{TiX}(\mathrm{X}=\mathrm{Fe}, \mathrm{Ni}, \mathrm{Pd}, \mathrm{Pt}$ and $\mathrm{Cu})$ alloys.

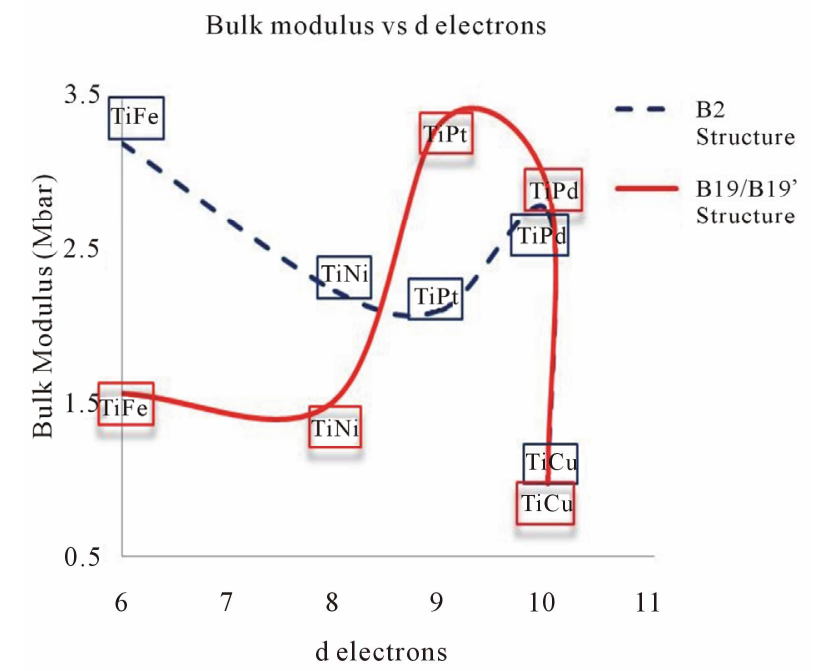

Figure 9. Variation of Bulk modulus as function of "d" electrons in $\mathrm{TiX}(\mathrm{X}=\mathrm{Fe}, \mathrm{Ni}, \mathrm{Pd}, \mathrm{Pt}$ and $\mathrm{Cu})$ alloy.

phase. In case of B2 phase, we infer bulk modulus values to decrease gradually as a function of $\mathrm{d}$ electrons except for TiPd. The $\mathrm{B}_{0}$ value is higher for TiPd than for TiPt. The $T_{m}$ is defined by both bulk modulus and the shear modulus. So, the observation of no systematic trend between $B_{o}$ and $T_{m}$ in $B 2$ phase indicates that the shear contribution varies significantly among these compounds in this phase. The bulk modulus of TiNi in B2 phase computed from our total energy study is $2.2984 \mathrm{Mbar}$ which is higher than the values $1.56 \mathrm{Mbar}$ reported by $\mathrm{Y}$. Ye et al. It has been experimentally and theoretically observed that the ternary alloying of $\mathrm{V}$ with TiNi $[23,24]$ will enhance the hardness of the alloy. The present work show that the hardness of TiPd is larger than that of TiNi 
hence alloying of TiNi with Pd substitution will improve the hardness of the material $[19,25]$.

\section{Conclusions}

We have performed first principles local density functional electronic structure calculation for the five TiX alloys $(\mathrm{X}=\mathrm{Fe}, \mathrm{Ni}, \mathrm{Pd}, \mathrm{Pt}$ and $\mathrm{Cu})$ using the TB-LMTO method. From our theoretical total-energy studies on TiX alloys we have arrived at the following conclusions:

- The calculated lattice constants are found to be in good agreement with experimental results.

- All alloys exist in B2 structure at ground state. The electronic properties are rather similar for these alloys as they have same number of valence electrons. If we look at fine details, the properties of $\mathrm{TiFe}$ and $\mathrm{TiNi}$ are similar and that of TiPd and TiPt are closer to each other than to TiNi.

- From the DOS histogram, we observe the lower energy part of the DOS curve to be dominated by the $\mathrm{X}$ metal $d$ states and the higher energy part dominated by the Ti $d$ states. The DOS at $\mathrm{E}_{\mathrm{F}}$ is mainly contributed by the Ti d states except for TiFe alloy wherein $d$ states of Fe show more dominance. The DOS localization accompanied by the spatial localization of $d$ electrons of $\mathrm{X}(\mathrm{X}=\mathrm{Fe}, \mathrm{Ni}, \mathrm{Pd}, \mathrm{Pt}, \mathrm{Cu})$ atoms results in weakening of the $\mathrm{d}-\mathrm{d}$ covalent bonds between the alloy components.

- The d-d hybridization is much pronounced for TiNi in B19' phase and p-d hybridization for TiPd and TiPt in B19 phase.

- The calculated heat of formation is higher for B19/ B19' structure showing a positive indication of strong directional bonding in (B19/B19') phase.

- The bulk modulus value is found to be higher for the $5 \mathrm{~d}$ series followed by $3 \mathrm{~d}$ and then by $4 \mathrm{~d}$ series of transition elements for $\mathrm{B} 2$ phase.

\section{REFERENCES}

[1] J. Morgiel, "Ordering of the $\beta$ Phase in TiNiCu and TiNiCuMn Melt Spun Ribbons Studied with the ALCHEMI Technique," Materials Chemistry and Physics, Vol. 81, No. 2-3, 2003, pp. 230-232. doi:10.1016/S0254-0584(02)00556-4

[2] S. A. Shabalovskaya, "Phase Transitions in the Intermetallic Compound TiNi with Charge-Density Wave Formation," Physica Status Solidi (B), Vol. 132, No. 2, 1985, pp. 327-344. doi:10.1002/pssb.2221320202

[3] Y. Y. Ye, C. T. Chan and K. M. Ho, "Structural and Electronic Properties of the Martensitic Alloys TiNi, TiPd and TiPt," Physical Review B, Vol. 56, No. 7, 1997, pp. 36783679. doi:10.1103/PhysRevB.56.3678

[4] H. L. Skriver, "The LMTO Method," Springer, Heidelberg, 1984.

[5] O. K. Anderson and O. Jepsen, "Explicit, First-Principles
Tight-Binding Theory," Physical Review Letters, Vol. 53, 1984, pp. 2571-2574. doi:10.1103/PhysRevLett.53.2571

[6] V. von Barth and L. Hedin, "A Local Exchange-Correlation Potential for the Spin Polarized Case," Journal of Physics C: Solid State Physics, Vol. 5, No. 13, 1972, pp. 1673-1642. doi:10.1088/0022-3719/5/13/012

[7] O. Jepsen and O. K. Anderson, "The Electronic Structure of h.c.p Ytterbium," Solid State Communications, Vol. 9, No. 20, 1971, pp. 1763-1767. doi:10.1016/0038-1098(71)90313-9

[8] P. Blochl, "Gesamtenergien, Kräfte und Metall-Halbleiter Grenzflächen (Total Energies, Forces and Metal-Semiconductor Interfaces," PhD Thesis, University of Stuttgart, Stuttgart, 1989.

[9] J. M. Zhang and G. Y. Guo, "Electronic and Phase Stability of Three Series of B2 Ti-Transition-Metal Compound," Journal of Physics: Condensed Matter, Vol. 7, No. 30, 1995, p. 6001. doi:10.1088/0953-8984/7/30/006

[10] M. Sanati, R. C. Albers and F. J. Pinski, "Electronic and Crystal Structure of NiTi Martensite," Physical Review B, Vol. 58, No. 20, 1998, pp. 13590-13593. doi:10.1103/PhysRevB.58.13590

[11] Y. Kudoh, M. Tokonami, S. Miyazaki and Kotsuka, "Crystal Structure of the Mertensite in Ti-49.2 at\% Ni Alloy Analyzed by the Single Crystal X-Ray Diffraction Method," Acta Metallurgica, Vol. 33, No. 11, 1985, pp. 2049-2056. doi:10.1016/0001-6160(85)90128-2

[12] P. Ravindran and R. Asokamani, "Electronic Structure, Phase Stability, Equation of State and Pressure Dependent Superconducting Properties of $\mathrm{Zr}_{3} \mathrm{Al}$," Physical Review B, Vol. 50, No. 2, 1994, pp. 668-673. doi:10.1103/PhysRevB.50.668

[13] V. L. Maruzz, J. F. Janak and K. Schwarz, "Calculated Thermal Properties of Metals," Physical Review B, Vol. 37, No. 2, 1988, pp. 790-799. doi:10.1103/PhysRevB.37.790

[14] A. Gyobu, Y. Kawamura, H. Horikawa and T. Saburi, "Martensitic Transformation and Two-Way Shape Memory Effect of Sputter-Deposited Ni-Rich Ti-Ni Alloy Films," Materials Science and Engineering: A, Vol. 273, 1999, pp. 749-753. doi:10.1016/S0921-5093(99)00409-8

[15] G. Bihlmayer, R. Eibler and A. Nickel, "Electronic Structure of B2-NiTi and -PdTi," Journal of Physics C: Solid State Physics, Vol. 5, 1993, pp. 5083-5090.

[16] H. J. Liu and Y. Ye, "Electronic Structure and Stability of Ti-Based Shape Memory Alloys by LMTO-ASA," Solid State Communications, Vol. 106, No. 4, 1998, pp. 197-202. doi:10.1016/S0038-1098(98)00008-8

[17] P. Ravindran and R. A. Asokmani, "Ground-State Properties and Relative Stability between the $\mathrm{Ll}_{2}$ and $\mathrm{DO}_{\mathrm{a}}$ Phases of $\mathrm{Ni}_{3} \mathrm{Al}$ by $\mathrm{Nb}$ Substitution," Physical Review B, Vol. 53, No. 3, 1996, pp. 1129-1137.

[18] S. A. Shabalovskaya and A. Narmonev, "Electronic Structure and Stability of Ti-Based B2 Shape-Memory Compounds: X-Ray and Ultraviolet Photoelectron Spectra," Physical Review B, Vol. 48, No. 18, 1993, pp. 1329613311. doi:10.1103/PhysRevB.48.13296

[19] G. Cacciamani, J. De keyzer, R. Ferro and U. E. Klotz, 
"Critical Evaluation of the Fe-Ni, Fe-Ti and Fe-Ni-Ti Alloy Systems," Intermetallics, Vol. 14, No. 11, pp. 1312-1325. doi:10.1016/i.intermet.2005.11.028

[20] J. Cai, D. S. Wang, S. J. Liu, S. Q. Duan and B. K. Ma, "Electronic Structure and B2 Phase Stability of Ti-based Shape-Memory Alloys," Physical Review B, Vol. 60, No. 23, 1999, pp. 15691-15698. doi:10.1103/PhysRevB.60.15691

[21] P. Vajeeston, P. Ravindran, C. Ravi and R. Asokamani, "Electronic Structure, Bonding, and Ground-State Properties of $\mathrm{AlB}_{2}$-Type Transition-Metal Diborides," Physical Review B, Vol. 63, No. 4, 2001, pp. 5115-5126. doi:10.1103/PhysRevB.63.045115

[22] G. Bozzolo, R. D. Noebe, H. O. Mosca, "Site Preference of Ternary Alloying Additions to NiTi: Fe, Pt, Pd, Au, Al,
$\mathrm{Cu}, \mathrm{Zr}$ and Hf," Journal of Alloys and Compounds, Vol. 389, No. 1-2, 2005, pp. 80-94. doi:10.1016/j.jallcom.2004.07.051

[23] R. F. Decker and J. R. Mihalisin, "Coherency Strains in $\gamma$ ' Hardened Nickel Alloys," Transactions of the American Society of Metals Quarterly, Vol. 62, 1969, pp. 481-489.

[24] J. H. Xu, T. Oquchi and A. J. Freeman, "Phase Stability and Magnetism of $\mathrm{Ni}_{3} \mathrm{Al}$," Physical Review B, Vol. 41, No. 8, 1990, pp. 5010-5016. doi:10.1103/PhysRevB.41.5010

[25] K. P. Mohancachandra, D. Shin and G. P. Carman, "Deposition and Characterization of Ti-Ni-Pd and Ti-Ni-Pt Shape Memory Alloy Thin Films," Smart Materials and Structures, Vol. 14, No. 5, 2005, pp. 312-316. doi:10.1088/0964-1726/14/5/021 